\title{
ISOLATED MAMMARY ECHINOCOCCOSIS
}

Madhumita Mukhopadhyay, Manas Kumar Dutta, Sudip Das, Bappaditya Halder, Raj Narayan Roy

1. Assistant Professor, Department of General Surgery, Calcutta National Medical College \& Hospital.

2. Senior Resident, Department of General Surgery, Calcutta National Medical College \& Hospital.

3. Post Graduate Student, Department of General Surgery, Calcutta National Medical College \& Hospital.

4. Post Graduate Student, Department of General Surgery, Calcutta National Medical College \& Hospital.

5. Professor, Department of General Surgery, Calcutta National Medical College \& Hospital.

\section{CORRESPONDING AUTHOR}

Madhumita Mukhopadhyay

Block 2, 7a, Ekta Heights,

56, Raja s. C. Mullick Road,

Kolkata - 700032,

E-mail: drmmeettuu@yahoo.co.in

Ph: 00919831397865 ,

ABSTRACT: Echinococcosis or hydatid disease is caused by the parasite Echinococcosis granulosus. Isolated or primary hydatid disease of the breast is very rare and accounts for less than $0.2 \%$ of all cases. Here we describe the case of an isolated hydatid cyst of the breast in a 25 year old female patient.

KEY WORDS: Hydatid cyst, Breast, Isolated

INTRODUCTION: Hydatid disease is endemic in central India (1). Echinococcus granulosus is the most common cause of hydatid disease in humans ( 2 ). Although more frequent reports have appeared in recent years, hydatid disease of the breast still remains rare and accounts for only 0.2 $\%$ of all occurrences $(2,3,4)$. Isolated cases are still rarer. We present the case of a primary hydatid cyst of the breast in a 25 year old woman.

CASE REPORT: A 25 year old woman presented to our hospital with a gradually progressive, painless lump in the upper outer quadrant of the left breast of 18 months duration. Her previous history was insignificant. She did not remember any close contact with any animal. Physical examination revealed a $4 \mathrm{~cm}$ by $3 \mathrm{~cm}$ lump in the upper outer quadrant of the left breast. The lump was non tender, firm and slightly mobile. The right breast was normal. There was no axillary lymphadenopathy or nipple discharge. Ultrasonography showed a cystic lesion with thick echogenic debris at the bottom ( Fig 1 ). Fine needle aspiration of the lump yielded $15 \mathrm{ml}$ of clear acellular fluid. The results of blood analysis, chest radiogram and abdominal ultrasonography were normal.

The lump was excised. On opening the cyst, we found a white, glistening membranous structure inside, partly separated from the cyst wall ( Fig 2 ). The cyst was unilocular and had thick walls. Microscopic section showed a laminated membrane ( Fig 3 ). The cyst wall showed dense mononuclear cell infiltrate. The patient was discharged home and treated with albendazole for three cycles.

DISCUSSION: Echinococcosis or hydatid disease is an "ancient" disease, well known for the past two thousand years. It has been encountered in various organs. Hydatid cyst is caused by the larva 
of Echinococcus granulosus and rarely, Echinococcus multilocularis (1). They are usually found in the liver and lungs, but they can develop anywhere in the body and have been reported in the spleen, kidney, muscles, bones, brain and retroperitoneum $(5,6)$. The breast is a very rare site accounting for less than $0.2 \%$ of all cases. It can be the only primary site or part of disseminated hydatidosis. It usually presents as a painless, slow-growing mass without regional lymphadenopathy and generally affects women between 30-50 years of age ( 7 ).

Radiological modalities for diagnosis of breast hydatid disease are ultrasound, mammography and MRI ( 2 ). Ultrasound is considered the method of choice for classification of the cysts. Gharbi et al have described five types of ultrasound findings for the hydatid cysts. They include pure fluid collection ( Type 1 ), fluid collection with a split wall ( Type 2 ), fluid collection with septa ( Type 3 ), heterogenous echo patterns ( Type 4 ) and reflecting thick walls (Type 5 ) ( 2, 8 ). Mammography may show a characteristic ring shaped structure inside a homogenous lesion ( 2 ). CT appearance of a hydatid cyst is of a low attenuation cystic mass with a high attenuation periphery ( 9 ). Cytological diagnosis by FNAC is established by the identification of scoleces, hooklets or fragments of laminated membrane ( 7 ). In our case cytology of the aspirated fluid was not diagnostic but negative cytology has been reported by others also ( 5 ).

The treatment of hydatid cyst of the breast is complete excision . Albendazole may decrease the recurrence rate of hydatid cyst disease. Recurrent cysts have been reported post operatively in a few patients. Albendazole may decrease the recurrence rate of hydatid cyst disease (10). To conclude, hydatid disease of the breast, though rare, should form part of the differential diagnosis of cystic diseases of the breast especially in an endemic country like ours (2). It may mimic a simple cyst, fibroadenoma, chronic abscess, phyllodes tumor or even a carcinoma (9). Awareness of the disease makes preoperative diagnosis easier and helps in the management by preventing spillage.

\section{REFERRENCES:}

1. Taori KB, Mahajan SM, Hirawe SR, Mundhada RG. Hydatid disease of breast. Breast Imaging 2004; 14(1): 57-602

2. Tutar N, Cakir B, Geyik E, Tarhan NC, Niron EA. Hydatid cysts in breast : mammography and ultrasound findings. Brittish Journal of Radiology 2006; 79(946): 114-116

3. Engin G, Acunas B, Rozanes I, Acunas G. Hydatid disease with unusual localization. Eur Radiol 2000;10:1904-12

4. Kiresi DA, Karabacakoglu A, Odev K, Karakose S. Uncommon locations of hydatid cysts. Acta Radiol 2003;44:622-36

5. Sah SP, Agarwal CS, Khan IR, Rani S. Hydatid cyst presenting as a breast lump. Southeast Asian J Trop Med Public Health 2000; 31(1): 185-86

6. Fisser a. Larval cestodes. In: Cox FEG, Kreier JP, Wakelin D, eds. Topley and Wilson's microbiology and microbial infections. Vol 5. Parasitology 9th ed, London : Arnold. 1998; 5: 539-60

7. Mohsin M, Mir IS, Shah NN, Fakir Sb, Quadir A. Hydatid disease of the breast : A case report. JIMA 2008; 40: 35-37

8. Gharbi HA, Hassine W, Brauner MW, Dupuch K. Ultrasound examination of the hydatic liver. Radiology 1981;139:459-63.

9. Masroor I, Azeemuddin M, Khan S, Barakzai A. Hydatid disease of the breast. Singapore medical journal 2010; 51(4): 72-75 
10. Uncu H, Erekul S. Hydatid cyst of the breast. Acta chir beig 2007; 107: 570-71

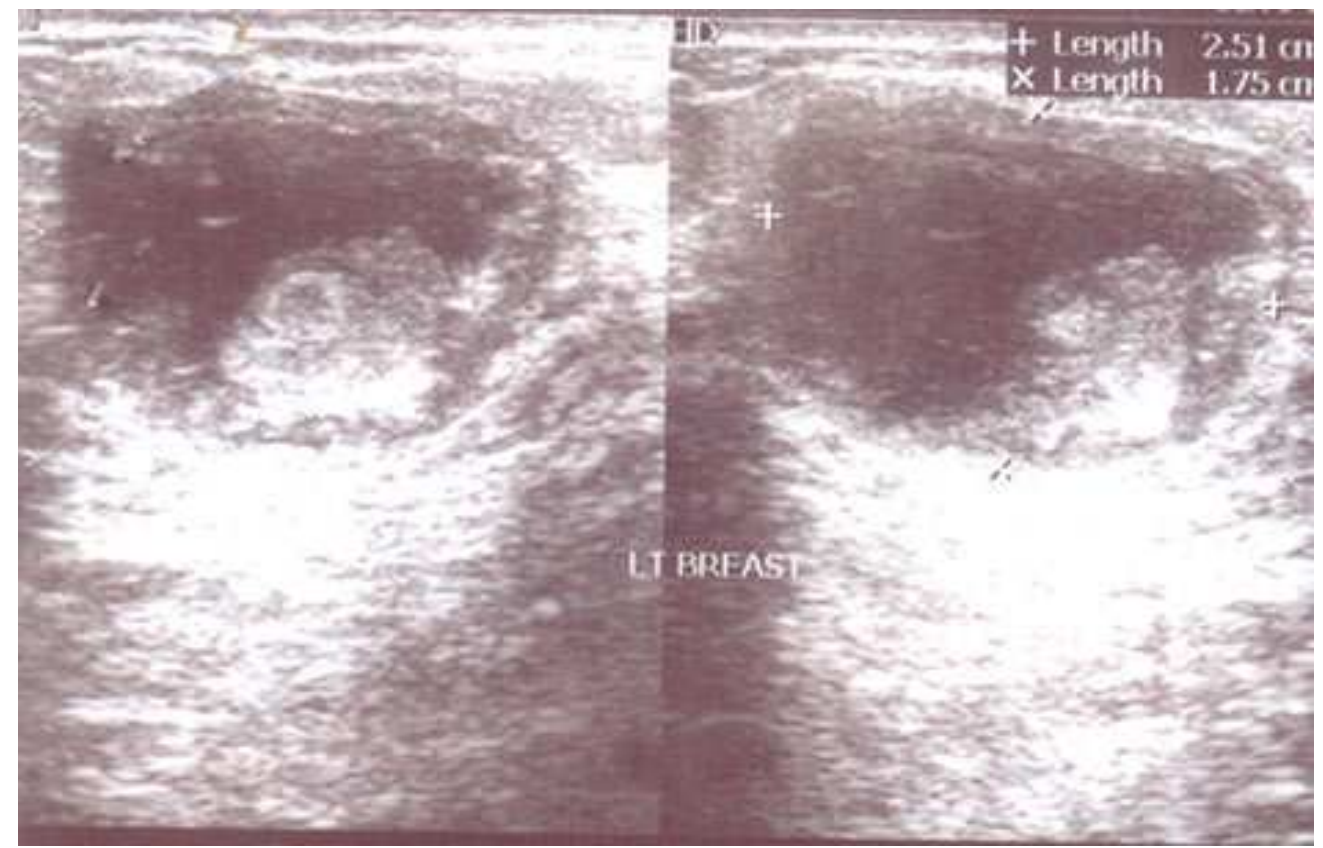

Fig 1: Ultrasonography showing a cystic lesion with debris at the bottom

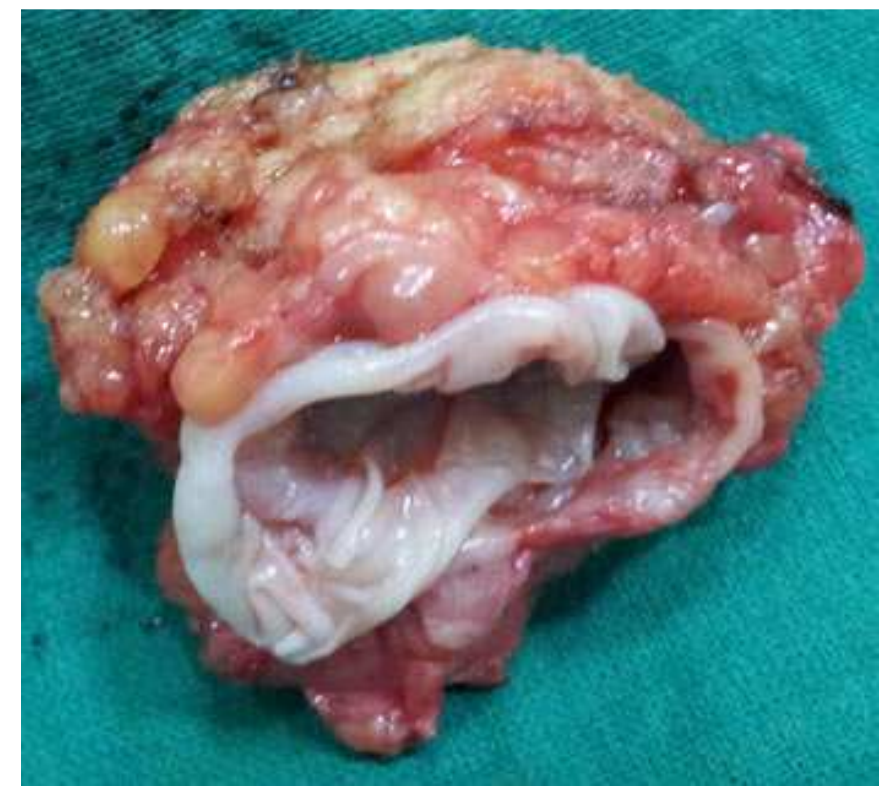

Fig 2: Cyst cavity with a white glistening membrane inside 


\section{CASE REPORT}

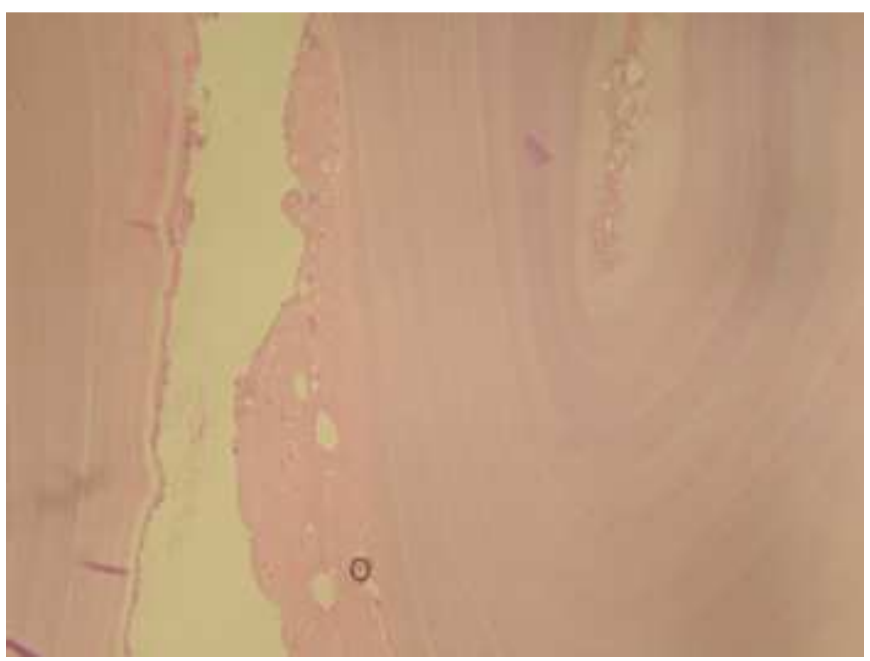

Fig 3: Histopathology showing laminated membrane 